BMJ Paediatrics Open

\title{
Smartphone app for neonatal heart rate assessment: an observational study
}

Susanna Myrnerts Höök (1) , ${ }^{1,2,3}$ Nicolas J Pejovic, ${ }^{1,2,3}$ Francesco Cavallin, ${ }^{4}$ Clare Lubulwa, ${ }^{5}$ Josaphat Byamugisha, ${ }^{5,6}$ Jolly Nankunda, ${ }^{5,7}$ Thorkild Tylleskär, ${ }^{1,8}$ Tobias Alfven (D) 2,3

To cite: Myrnerts Höök S, Pejovic NJ, Cavallin F, et al. Smartphone app for neonatal heart rate assessment: an observational study. BMJ Paediatrics Open 2020;4:e000688. doi:10.1136/ bmjpo-2020-000688

Received 26 March 2020 Revised 6 June 2020 Accepted 8 June 2020

\section{Check for updates}

(C) Author(s) (or their employer(s)) 2020. Re-use permitted under CC BY-NC. No commercial re-use. See rights and permissions. Published by BMJ.

${ }^{1}$ Department of Global Public Health and Primary Care, Centre for International Health, University of Bergen, Bergen, Norway

${ }^{2}$ Department of Global Public Health, Karolinska Institutet, Stockholm, Sweden

${ }^{3}$ Sachs' Children and Youth Hospital, Stockholm, Sweden ${ }^{4}$ Independent Statistician, Solagna, Italy

${ }^{5}$ Mulago National Referral Hospital, Kampala, Uganda ${ }^{6}$ Department of Obstetrics and Gynaecology, College of Health Sciences, Makerere University, Kampala, Uganda

${ }^{7}$ Department of Paediatrics and Child Health, College of Health Sciences, Makerere University, Kampala, Uganda

${ }^{8}$ Centre for Intervention Science in Maternal and Child Health, University of Bergen, Bergen, Norway

Correspondence to Dr Susanna Myrnerts Höök; susanna.hook@uib.no

\section{ABSTRACT}

Background Heart rate (HR) assessment is crucial in neonatal resuscitation, but pulse oximetry (P0) and electrocardiography (ECG) are rarely accessible in lowresource to middle-resource settings. This study evaluated a free-of-charge smartphone application, NeoTap, which records HR with a screen-tapping method bypassing mental arithmetic calculations.

Methods This observational study was carried out during three time periods between May 2015 and January 2019 in Uganda in three phases. In phase 1, a metronome rate $(n=180)$ was recorded by low-end users (midwives) using NeoTap. In phase 2, HR ( $n=69)$ in breathing neonates was recorded by high-end users (paediatricians) using NeoTap versus $P 0$. In phase $3, H R(n=235)$ in non-breathing neonates was recorded by low-end users using NeoTap versus ECG.

Results In high-end users the mean difference was 3 beats per minute (bpm) higher with NeoTap versus PO (95\% agreement limits -14 to $19 \mathrm{bpm}$ ), with acquisition time of 5 seconds. In low-end users, the mean difference was 6 bpm lower with NeoTap versus metronome (95\% agreement limits -26 to $14 \mathrm{bpm}$ ) and $3 \mathrm{bpm}$ higher with NeoTap versus ECG in non-breathing neonates (95\% agreement limits -48 to $53 \mathrm{bpm}$ ), with acquisition time of 2.7 seconds. The agreement between NeoTap and ECG was good in the HR categories of $60-99 \mathrm{bpm}$ and $\geq 100 \mathrm{bpm}$; $\mathrm{HR}<60 \mathrm{bpm}$ had few measurements (kappa index 0.71, $95 \% \mathrm{Cl} 0.63$ to 0.79 ).

Conclusion HR could be accurately and rapidly assessed using a smartphone application in breathing neonates in a low-resource setting. Clinical assessment by lowend users was less accurate with wider $\mathrm{Cl}$ but still adds clinically important information in non-breathing neonates. The authors suggest low-end users may benefit from auscultation-focused training. More research is needed to evaluate its feasibility in clinical use.

\section{INTRODUCTION}

Neonatal deaths stand at $47 \%$ of all deaths in children $<5$ years of age, equal to 2.5 million neonates dying in 2017, with about 1 million dying on the first day. ${ }^{12}$ Intrapartum-related events (birth asphyxia) stand at around 0.66 million deaths (uncertainty range of 0.42-1.05 million). ${ }^{3} \quad$ Moreover, 2.6 million stillbirths occur every year, $50 \%$ after the onset of labour. ${ }^{4}$ Successful resuscitation

\section{What is known about the subject?}

- Heart rate is crucial in evaluating the status of neonates during resuscitation.

- Previous simulation studies and an animal model have shown that a smartphone application, NeoTap, offers fast and accurate heart rate monitoring.

- Clinical data on heart rate monitoring of neonates with a smartphone app are not yet available.

\section{What this study adds?}

A smartphone application can improve speed and accuracy during heart rate assessment of neonates by auscultation in clinical setting.

- NeoTap could be a low-cost alternative to expensive medical equipment in both low-resource and highresource settings.

could prevent many early neonatal deaths and decrease the morbidity of neonates surviving

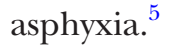

Heart rate (HR) is one of the most important clinical parameters in evaluating the status of a neonate, to guide neonatal resuscitation and to predict early neonatal mortality and morbidity. ${ }^{6-8}$ International guidelines state that resuscitation efforts should be guided by checking respiration and HR. ${ }^{79}$ Pulse oximetry (PO) is valuable in monitoring $\mathrm{HR}$ and measuring oxygen saturation, ${ }^{10}{ }^{11}$ but HR is measured faster and more accurately through electrocardiography (ECG) ${ }^{79}$ Auscultation, recommended when PO and ECG are unavailable, is often inaccurate. ${ }^{12-16}$ Doppler is not recommended in current international guidelines. ${ }^{79}$ Resource-limited settings rarely have PO, ECG or Doppler. ${ }^{17}$ In 2017, a systematic review investigated the accuracy of seven new technologies for monitoring HRs of neonates and concluded that none could be recommended as suitable for widespread clinical use at this stage. ${ }^{18}$ The need to develop a low-cost, rapid and accurate alternative method for 

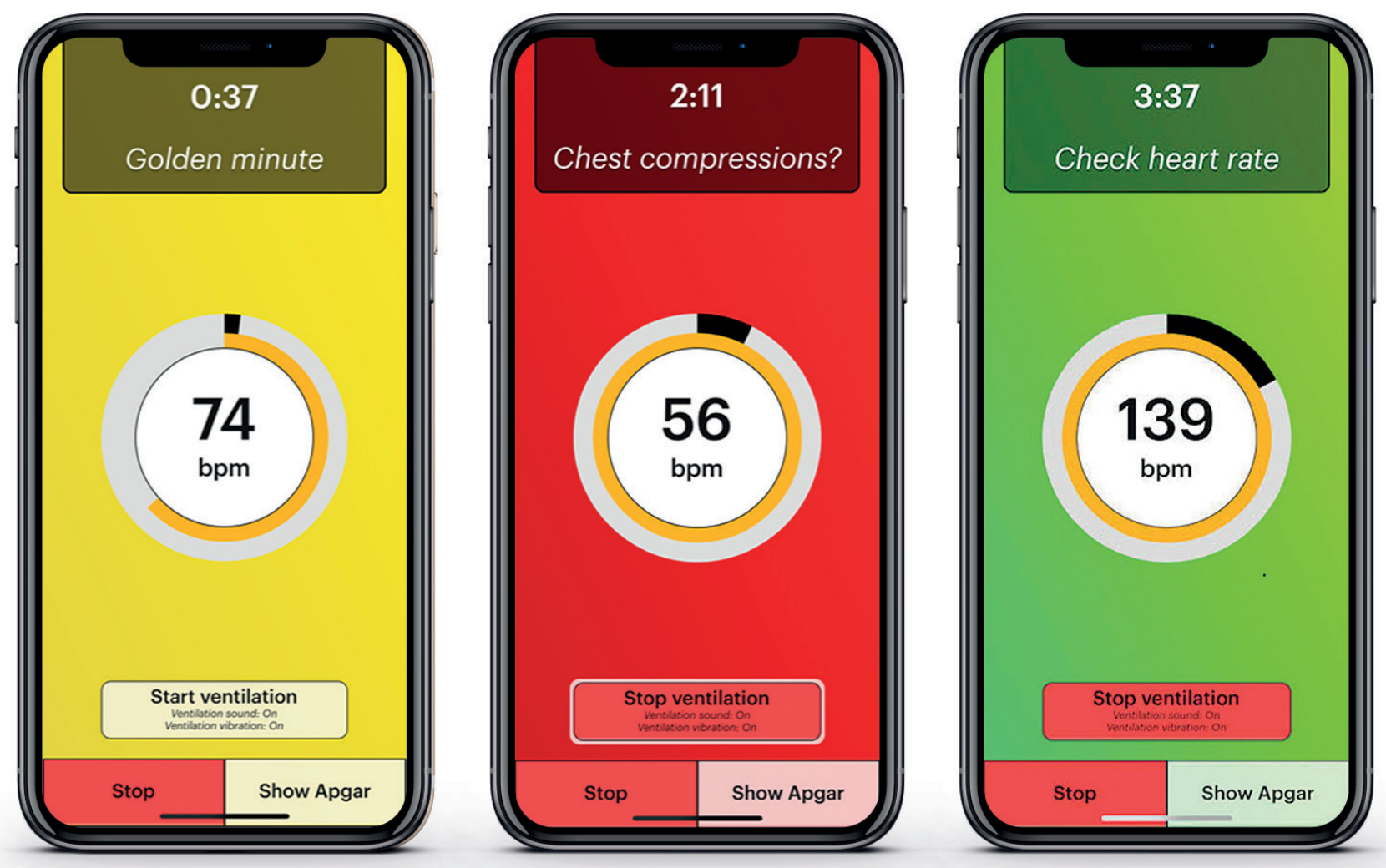

Figure 1 Tap to record the neonate's heart rate by the NeoTap application. Heart rate $<100$ bpm (yellow) at $37 \mathrm{~s}$ : prepare for ventilation. Heart rate $<60 \mathrm{bpm}$ (red) at $2 \mathrm{~min}$ and $11 \mathrm{~s}$ : start chest compressions? Heart rate $\geq 100 \mathrm{bpm}$ (green) at $3 \mathrm{~min}$ and $37 \mathrm{~s}$ : neonatal resuscitation is going well. bpm, beats per minute.

monitoring HR during neonatal resuscitation has been highlighted. ${ }^{18} 19$

NeoTap (NeoTap Life Support-NeoTapLS) is a free-ofcharge smartphone app for HR recording (Google Play and App Store), developed by a non-profit organisation (Tap4Life, Stockholm, Sweden). ${ }^{20}{ }^{21}$ It uses a screentapping method; the user auscultates the heart sounds and taps the beat on the screen a minimum of three times, and the app generates a number, bypassing mental arithmetic (figure 1). No probes are needed, and the interface is functional even when protected inside a latex glove. The app can also be used to estimate cord pulsations and fetal HR; an instructional video on 'How to use NeoTapLS' is available in online supplementary file 2 and the full version is available on YouTube. A significant proportion of health personnel in low-resource settings have their own smartphone, a number that is increasing. ${ }^{22}$ NeoTap has shown promising results from three simulation studies and an animal model. ${ }^{23-26}$

The aim of our study was to evaluate NeoTap by determining the speed and accuracy at which users could assess a rhythm by a metronome (low-end users, midwives well familiar with neonatal resuscitation but with no prior experience of the tapping method), HR in breathing neonates (high-end users, paediatricians well familiar with the tapping method), and HR in neonates in need of positive pressure ventilation (PPV), equal to neonates with insufficient or no breathing at birth (low-end users). The hypothesis was that NeoTap is as fast or faster than PO and ECG and accurate enough to guide neonatal resuscitations.

\section{METHODS}

\section{Study design}

This prospective observational study was carried out during three time periods between May 2015 and January 2019. It is a substudy of the 'Randomized Clinical Trial Assessing Laryngeal Mask Airway Versus Face-Mask Ventilation in Neonatal Resuscitation (LMA vs FMV)' (ClinicalTrials.gov NCT02042118) and the 'Neonatal Resuscitation with Supraglottic Airway Trial (NeoSupra)' (ClinicalTrials.gov NCT03133572), conducted at the Department of Obstetrics and Gynaecology, Mulago National Referral Hospital, Uganda, which has around 25000 deliveries per year.

\section{Data collection}

The study had three phases to evaluate NeoTap by testing low-end users' ability to tap a metronome rhythm and high-end and low-end users' ability to tap a correct HR in clinical practice, as well as assess the swiftness of the method in clinical use. Low-end users in the first and third phases were research midwives and exposed on a daily 


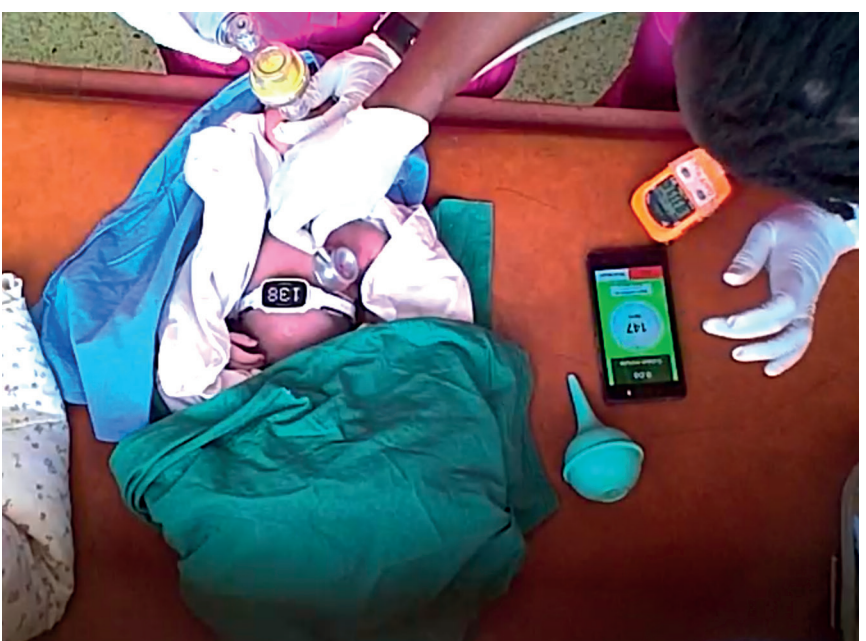

Figure 2 Low-end user using NeoTap to record heart rate (heart rate shown 147) and dry-electrode electrocardiography (heart rate shown 138). Picture used with written permission from the parents.

basis to neonatal resuscitation and trained according to Helping Babies Breathe, as part of the NeoSupra trial. ${ }^{27}$ High-end users were two paediatric specialists. The users simultaneously tapped the pace of the rhythm of the metronome, or the HR they auscultated over the heart of the neonate, on the smartphone screen with the NeoTap app running. NeoTap is designed to display the average rate of the last three taps, meaning a number was displayed after a minimum of three taps (figure 2 ). The metronome was used as the true value in phase 1 , HR by PO (PalmSAT 2500, Nonin Medical, Plymouth, USA) as the true value in phase 2 (no other monitoring equipment was available at the time), and HR by ECG as the true value in phase 3 . A convenience sample was chosen for each phase due to practical reasons and the exploratory nature of the study.

Phase 1: metronome rate by NeoTap (low-end users, a simulation) In phase 1 we assessed the ability of low-end users to correctly record an audible metronome rhythm. Ten rates were randomly selected using a number generator set over the range of $20-150$ beats per minute $(\mathrm{bpm}),{ }^{28}$ and the rates (masked to the participants) were presented by the metronome for approximately $20 \mathrm{~s}$. Low-end users recorded the rate with the NeoTap, after first being introduced to the app for 3-5 min, and wrote down the rate obtained on separate papers. The midwives included in the study were chosen irrespective of prior experience of smartphones. Informed consent was obtained from all participants.

\section{Phase 2: HR by NeoTap versus PO (high-end users, healthy} neonates)

In phase 2, we assessed the swiftness and ability of two high-end users to accurately record HR using NeoTap compared with PO in neonates not in need of PPV. PO was placed on the neonate on arrival on the resuscitation table by one high-end user and HR was assessed using
NeoTap by the second high-end user as soon as HR was displayed by PO. Directly after HR was assessed using NeoTap, the second high-end user checked the HR on the PO (not masked to the participants) and noted both HRs on a paper. Acquisition time of NeoTap was noted (defined in seconds from start to end of tapping). Data were collected on-site when high-end users were available, and it was at this stage when it was unfeasible to involve low-end users since few were available. The first four paired HRs per neonate were collected. Informed consent was obtained from the parents on maternal admission and from the high-end users.

Phase 3: HR by NeoTap versus ECG (low-end users, neonates in need of PPV)

In phase 3, we assessed the swiftness and ability of low-end users to accurately record HR using NeoTap compared with ECG in neonates in need of PPV. ECG was placed on the neonate once feasible and HR was assessed using NeoTap when HR was displayed by ECG and compared with HR obtained by ECG at the same time (not masked to the participants). Low-end users were already introduced to NeoTap in phase 1 and did not receive additional training prior to phase 3 . The acquisition time of NeoTap was noted as in phase 2. No high-end users were available at the study site, and it was therefore not possible to include them. All resuscitations were video-recorded using an HD 1080P Black Box AI-IP018 camera (Shenzhen Aishine Electronics, China). The first $49 \mathrm{HR}$ data were supervised by the researchers and collected on-site by traditional ECG (Philips Intellivue X2, Amsterdam, The Netherlands), and the rest were unsupervised and collected from video review with dry-electrode ECG (NeoBeat, Laerdal Global Health, Stavanger, Norway). All paired HRs (HR by NeoTap at the same time as HR by ECG) until end of resuscitation were collected; no upper limit was set for numbers of assessments per neonate (figure 2). All neonates lacking simultaneous data (only one device, poor signal acquisition or poor camera angle) were excluded $(n=270)$. Data on Apgar and weight were double-entered using Android devices running the Open Data Kit V.2.0 tool suite. ${ }^{29}$ Written and oral information was given to all parents on maternal admission, and deferred consent was obtained post-hoc in cases needing resuscitation. $^{27}$

\section{Patient and public involvement}

It was not appropriate to involve patients or the public in the design, or conduct, or reporting or dissemination plans for the study.

\section{Data analysis}

The agreement in phase 1 was assessed using a BlandAltman plot (including Pearson's correlation coefficient between HR difference and HR values). The agreement in phase 2 and 3 was assessed using a Bland-Altman plot for repeated measures (including repeated measure correlation between HR difference and HR values), and 


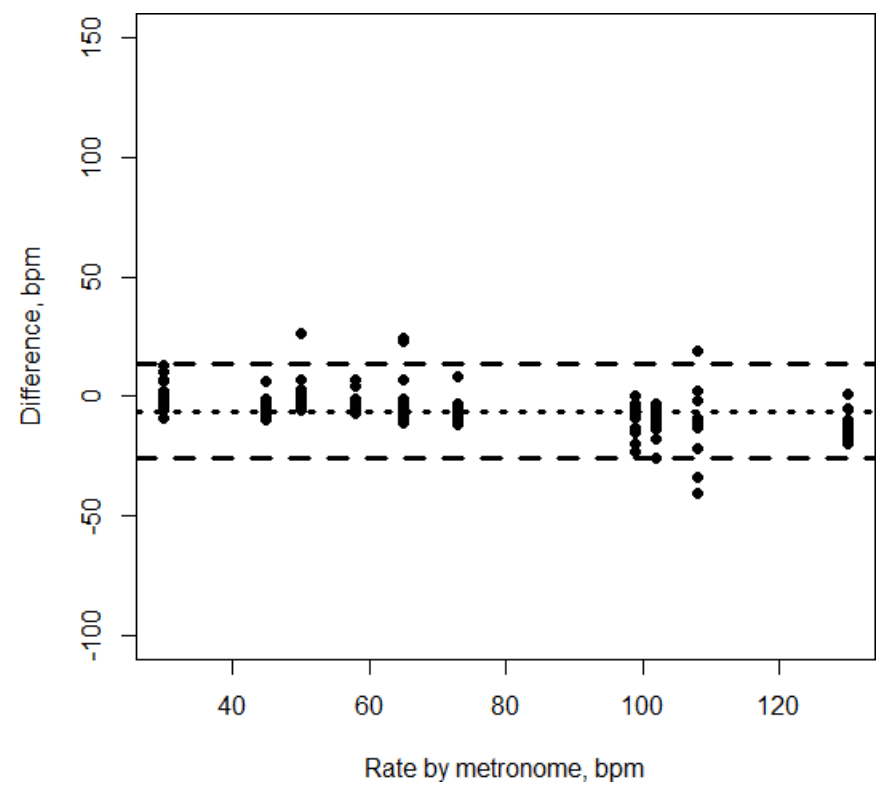

Figure 3 Agreement between the metronome rhythm and the rate low-end users recorded using NeoTap: a simulation. Metronome rhythm is shown on the $\mathrm{x}$-axis and the difference from recordings done by NeoTap on the y-axis (Bland-Altman plot) (data set in online supplementary file). bpm, beats per minute.

in phase 3 using repeated measures version of kappa index on the following HR categories: <60, 60-99 and $\geq 100 \mathrm{bpm}$. The sensitivity and specificity of NeoTap in detecting bradycardia ( $\mathrm{HR}<100 \mathrm{bpm}$ ) were also calculated. Acquisition times in phase 2 and 3 were summarised with median and IQR for descriptive purposes.

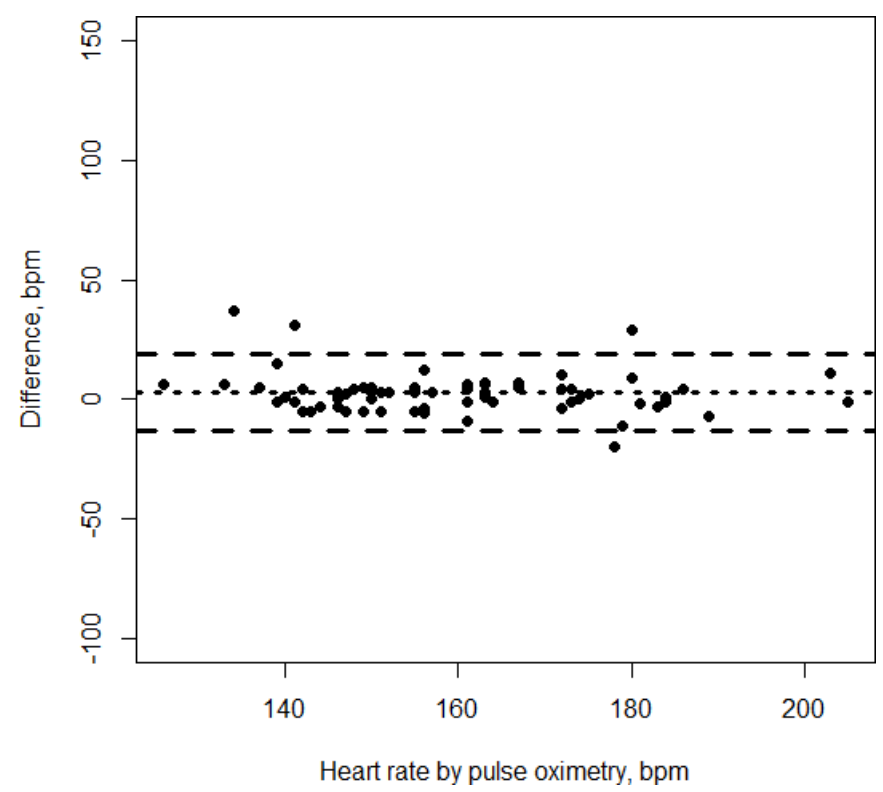

Figure 4 Agreement between NeoTap and pulse oximetry among high-end users recording heart rate in healthy breathing neonates. Pulse oximetry recording is shown on the $x$-axis and the difference between the readings on the $y$-axis (Bland-Altman plot) (data set in online supplementary file). bpm, beats per minute.
Table 1 Characteristics of neonates in phase 2 and 3 of the study

\begin{tabular}{|c|c|c|}
\hline Characteristics & Phase 2 & Phase 3 \\
\hline $\begin{array}{l}\text { Number of } \\
\text { neonates }\end{array}$ & 33 & 98 \\
\hline $\begin{array}{l}\text { Number of } \\
\text { recordings }\end{array}$ & 69 & 235 \\
\hline In need of PPV & No & Yes \\
\hline Apgar 1 min & 9 (IQR 9-9) & 3 (IQR 2-4) \\
\hline Apgar $5 \mathrm{~min}$ & 9 (IQR 9-10) & 5 (IQR 4-6) \\
\hline Median weight (g) & $\begin{array}{l}3000 \text { (IQR 2700- } \\
3390)\end{array}$ & $\begin{array}{l}3100 \text { (IQR 2750- } \\
3400)\end{array}$ \\
\hline $\begin{array}{l}\text { Time of HR } \\
\text { assessment after } \\
\text { birth (s) }\end{array}$ & $\begin{array}{l}\text { 120-1800 (median } \\
300, \text { IQR 180-600) }\end{array}$ & $\sim 100-720^{*}$ \\
\hline
\end{tabular}

${ }^{*}$ Exact data on time for measurements not possible to obtain through the method used in phase 3 .

$\mathrm{HR}$, heart rate; PPV, positive pressure ventilation.

Statistical analysis was performed using R V.3.5 (R Foundation for Statistical Computing, Vienna, Austria). ${ }^{30}$

\section{RESULTS}

During the three phases we had no issues with the reliability of the app. The app is designed to use very low resources from the phone and is continuously updated. It never crashed and froze and no battery problems occurred. The quality of the videos in phase 3 was excellent, with only a few exclusions due to non-visible HR on NeoTap or ECG.

Phase 1: metronome rate by NeoTap (low-end users, a simulation)

One hundred and eighty recordings were assessed by 18 low-end users. There was a mean difference of $-6 \mathrm{bpm}$ with NeoTap versus metronome, with $95 \%$ agreement limits of -26 to $14 \mathrm{bpm}$ (Bland-Altman plot) (figure 3). The difference was inversely correlated with the metronome rhythm $(\mathrm{r}=-0.50, \mathrm{p}<0.0001)$, moving from an overestimation to an underestimation. NeoTap recordings ranged from 21 to $131 \mathrm{bpm}$, and the metronome was set at a range of $30-130 \mathrm{bpm}$. In total $77 \%$ differed by 10 or less from the true value and $95 \%$ differed by 20 or less.

\section{Phase 2: HR by NeoTap versus PO (high-end users, healthy neonates)}

Sixty-nine HR recordings were assessed on 33 neonates as soon as HR by PO was available, which was at $120 \mathrm{~s}$ or more after birth (table 1). There was a mean difference of $3 \mathrm{bpm}$ with NeoTap versus PO, with $95 \%$ agreement limits of -14 to $19 \mathrm{bpm}$ (Bland-Altman plot) (figure 4). The difference was inversely correlated with $\mathrm{HR}(\mathrm{r}=-0.43$, $\mathrm{p}=0.009$ ); it decreased, not towards a zero difference, but towards a negative difference. HR ranged from 132 to 214 bpm with NeoTap, and from 126 to $205 \mathrm{bpm}$ with PO. The median acquisition time for the estimated $\mathrm{HR}$ was $5 \mathrm{~s}$ 


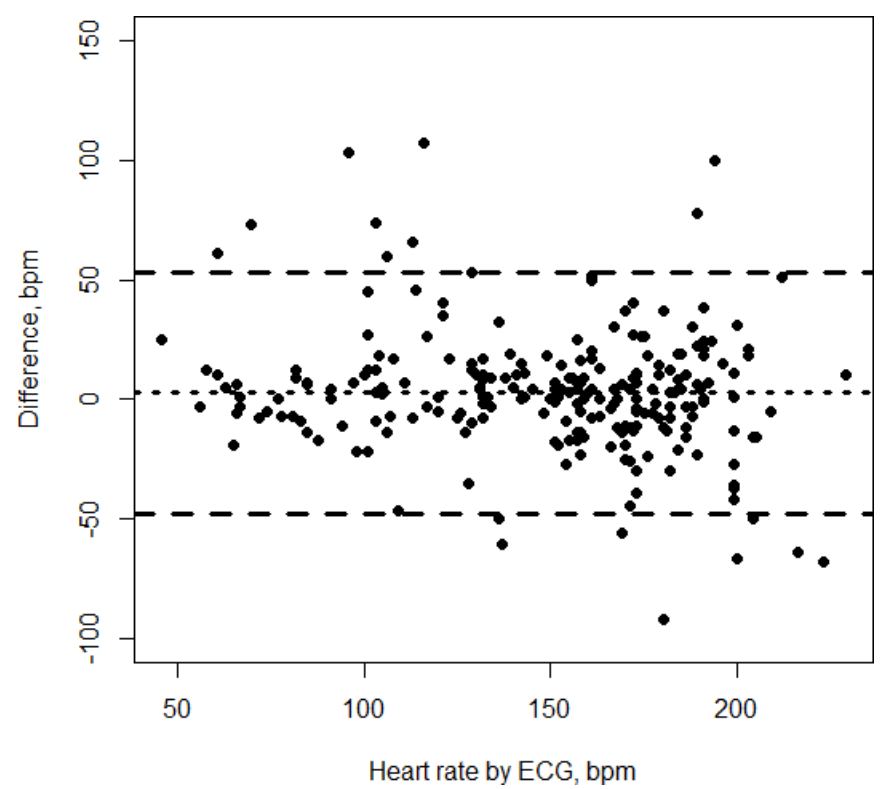

Figure 5 Agreement between NeoTap and ECG among low-end users recording heart rate in non-breathing neonates during neonatal resuscitation. ECG recordings are shown on the $\mathrm{x}$-axis and the difference between the readings on the $y$-axis (Bland-Altman plot) (data set in online supplementary file). bpm, beats per minute; ECG, electrocardiography.

(IQR 5-5), ranging from 3 to $15 \mathrm{~s}$. In total, $88 \%$ differed by 10 or less from the true value and $96 \%$ differed by 20 or less.

\section{Phase 3: HR by NeoTap versus ECG (low-end users, neonates} in need of PPV)

Two hundred and thirty-five HR recordings were assessed by approximately 18 low-end users on 98 neonates (table 1). There was a mean difference of $3 \mathrm{bpm}$ with NeoTap versus ECG, with $95 \%$ agreement limits of -48 to $53 \mathrm{bpm}$, a difference that did not correlate with HR $(\mathrm{r}=-0.06, \mathrm{p}=0.51)$ (Bland-Altman plot) (figure 5). HR ranged from 46 to $294 \mathrm{bpm}$ with NeoTap, and from 46 to 229 bpm with ECG. The median acquisition time for the estimated $\mathrm{HR}$ was $2.7 \mathrm{~s}$ (IQR 1.7-4.7), ranging from 0.8 to $13.9 \mathrm{~s}$. When HR was evaluated using the categories $<60$, $60-99$ and $\geq 100 \mathrm{bpm}$ (table 2), the agreement between NeoTap and ECG was good (kappa index $0.71,95 \%$ CI 0.63 to 0.79 ). The $<60 \mathrm{bpm}$ category included only three

Table 2 Distribution in categories of correctly and incorrectly recorded heart rates among midwives assessing neonates in need of positive pressure ventilation compared with electrocardiography, phase 3

\begin{tabular}{llll}
\hline NeoTap & \multicolumn{3}{l}{ Electrocardiography } \\
\hline & $<60 \mathrm{bpm}$ & $60-99 \mathrm{bpm}$ & $\geq 100 \mathrm{bpm}$ \\
\hline $60 \mathrm{bpm}$ & 1 & 1 & 0 \\
$60-99 \mathrm{bpm}$ & 2 & 22 & 8 \\
$\geq 100 \mathrm{bpm}$ & 0 & 4 & 197 \\
\hline
\end{tabular}

Data expressed as number of evaluations in each category.

bpm, beats per minute. recordings, with NeoTap differing $+3,-12$ and -25 from ECG. The 60-99 bpm category included 27 recordings differing by a median of 7 (IQR 5-14) from the true value, and the $>100 \mathrm{bpm}$ category included 205 recordings differing by a median of 12 (IQR 5-24) from the true value. In total, $48 \%$ differed 10 or less from the true value and $73 \%$ differed by 20 or less. Overall, NeoTap showed very good sensitivity $(0.87)$ and specificity $(0.96)$ in detecting bradycardia ( $\mathrm{HR}<100 \mathrm{bpm})$.

The complete data set for all three phases is available in online supplementary file.

\section{DISCUSSION}

This study presents new data on the feasibility of using a smartphone app for swift and accurate HR assessments in neonates, both those in need and not in need of PPV. NeoTap showed variable accuracy and precision in estimating rates and HRs, especially in low-end users in HR auscultation. Low-end users could quickly learn the tapping technique and both high-end and low-end users were quick in estimating HRs.

In low-resource settings, neonatal resuscitation is mainly carried out by health personnel with limited experience in both airway management and auscultation. Reliable monitoring equipment is rarely available. ${ }^{17}$ HR assessment is inaccurate due to imprecise auscultation and palpation or errors in mental arithmetic calculation. ${ }^{12-1631}$ Auscultation is a three-step procedure: first is auscultating the heart, second is understanding what you hear (first and second heart sounds) and third is translating it by calculation to provide a number. A recent clinical study showed that HR auscultation by clinicians compared with PO and ECG was quick and reasonably accurate in neonates not in need of PPV. Still, studies during neonatal resuscitation with less experienced health personnel are lacking. ${ }^{32}$ Although imprecise, international guidelines recommend HR determination by physical examination if no PO and/or ECG are available. ${ }^{79}$

NeoTap over-rides the need for mental arithmetic calculations. In 2018, two simulation studies reported that HR could be accurately and rapidly assessed using NeoTap on a manikin. ${ }^{23}{ }^{24}$ In 2019, another simulation study showed that NeoTap reduced the time to the first HR and the time to initiate heart compressions and to administer epinephrine compared with auscultation and mental computation..$^{25}$ A porcine model showed that HR assessment with NeoTap had similar accuracy compared with auscultation with a digital stethoscope, ECG or carotid blood flow during asphyxia and faster acquisition time compared with the $6 \mathrm{~s}$ or $10 \mathrm{~s}$ method with a digital stethoscope. ${ }^{26}$ However, data on the clinically important group of $\mathrm{HR}<60 \mathrm{bpm}$ are few and show contradictory results in the studies above as well as in the present study. A recent review on HR assessment stated that novel technologies including tap-based applications can support 
HR assessment, but that their clinical efficacy during neonatal resuscitation has yet to be investigated. ${ }^{33}$

The accuracy in this study was highest among low-end users recording a metronome rhythm and in high-end users recording $\mathrm{HR}$ compared with $\mathrm{PO}$ in neonates not in need of PPV. In phase 1 there was an inverse correlation between the bpm presented and the difference-participants overestimate low beats and underestimate high beats. We think this is because in low rates it is easy to tap too early and be too eager to tap the screen even when no sounds are presented, and in high rates it is hard to keep the high speed if you are not used to the tapping technic. In clinical use, this effect may be problematic in low HRs, but in high HRs it has minor clinical implications. Lowend users demonstrated the same mean difference in phase 3 as high-end users in phase 2, but with wider $95 \%$ agreement limits. Some recordings seemed to be twice the actual value. Health personnel, inexperienced in listening to hearts, may tap on both the first and second heart sounds, that is, tapping twice for each heart beat, a potential risk for errors in HR calculation even when auscultating without support from NeoTap. A qualitative study in our setting revealed that midwives did not assess HR by auscultation before the start of this study. Instead they palpated the cord or the chest. ${ }^{34}$ The midwives, however, accurately assessed the metronome rhythm. Auscultation-focused training and awareness of the first and second heart sounds could potentially improve clinical HR assessment with the tapping method. Clinical studies have shown that training is crucial and repeated training of health personnel affects the management of patients. ${ }^{356}$ It is likely that clinicians would have obtained better results due to prior experience in HR auscultation, and a training module for HR auscultation in resuscitation simulators could probably improve auscultation skills and performance of low-end users. Phase 3 shows few disagreements and narrow IQR ranges, and approximately three-fourths of HRs differed 20 or less from the true value in the $60-99 \mathrm{bpm}$ and $\geq 100 \mathrm{bpm}$ categories, pointing at a high probability of adhering to guidelines.

There is need for a low-cost, rapid and accurate alternative method for monitoring HR during neonatal resuscitation in low-resource to middle-resource settings. Rapid and accurate decision-making is crucial in neonatal resuscitation and $\mathrm{PO}$ is too slow to fulfil international resuscitation guidelines. ${ }^{7937} \mathrm{ECG}$ is fast and accurate but may be difficult to apply on the wet torso of the neonate, leading to delayed application. ${ }^{38}{ }^{39}$ NeoTap or other apps for HR assessment are potentially faster than PO and ECG, offering an alternative way to fulfil international guidelines. ${ }^{24}{ }^{25}$ However, the reported acquisition times in phase 3 were possibly due to a misunderstanding of the 'tap at least three times for HR' feature of the app. Users should be reminded to tap until they feel confident of tapping the same pace as the HR they hear, still a swift method potentially leading to higher accuracy.

There are limitations to this study. Low-end users were skilled in neonatal resuscitation and were trained in
Helping Babies Breathe shortly before the study started. The participants were part of an ongoing trial providing a better environment for auscultation. Less experienced healthcare providers in rural areas may produce inferior results. The gold standard is different for each of the three phases due to practical reasons, for example lack of ECG at the study site during phase 2. PO has high sensitivity and specificity but may display a too low HR during the first minutes of life. ${ }^{40} \mathrm{PO}$ in this study was used in neonates not in need of PPV at $120 \mathrm{~s}$ or more after birth, supporting the reliability of the PO data, and since NeoTap showed slightly higher HRs it points at NeoTap being accurate. The participants in phase 2 and 3 were not masked to the true value, introducing a potential bias, but the algorithm of NeoTap displays the average rate of the last three taps. This, combined with the very short acquisition times in both phases, de-emphasises this point. We had different users in the respective phases for practical reasons, making it harder to generalise the results. Most of the HR assessments in phase 3 were unsupervised, meaning timing of placement of ECG and first HR assessment was up to the user. Also, in phase 3, we could not identify the users since only the hands were caught on the videos; therefore, the number of users in this phase is an approximation. Lastly, we had few measurements of $\mathrm{HR}<100 \mathrm{bpm}$ and especially $<60 \mathrm{bpm}$, limiting the possibility of evaluating the importance of the results in clinical practice.

\section{CONCLUSION}

NeoTap provides a low-cost technology well adapted to the context of low-resource settings. It can be used in an inexpensive smartphone for swift and accurate HR registration. Clinical assessment by low-end users was less accurate and the authors suggest they may benefit from auscultation-focused training. Further studies are needed to demonstrate whether smartphone apps are useful in clinical practice.

\section{Twitter Susanna Myrnerts Höök @SavingNeonates}

Acknowledgements We would like to especially thank Miss Hadija Nalubwama, trial manager, for her invaluable contributions to the study. Our greatest thanks to the staff at the Maternity and Special Care Unit of Mulago National Referral Hospital, Kampala, Uganda, for their amazing struggle to improve the care of neonates.

Contributors SMH was responsible for the study design, preparation of the study site, acquisition of data, data analysis and interpretation of data. She conducted the literature search and was responsible for the writing process of the manuscript and approval of the final draft. NJP contributed to study design and acquisition of data. He revised the work draft and approved the final draft. FC, an independent statistician, contributed to the analyses of the data. He revised the work draft and approved the final draft. CL, JB and JN contributed to study design, manuscript revision and approved the final draft. TT contributed to interpretation of data, manuscript revision and approved the final draft. TA contributed to the study design, data analysis, manuscript revision and approval of the final draft.

Funding The work was supported by the Laerdal Global Health Foundation, the Research Council of Norway through FRIMEDBIO grant 250531 , and by the Centre for Intervention Science in Maternal and Child Health (CISMAC; project number 223269), which is funded by the Research Council of Norway through its Centre of Excellence scheme, and the University of Bergen, Norway. In-kind contributions 
were received from the University of Bergen, Makerere University and the Karolinska Institutet.

Disclaimer The funding agencies had no involvement in the study or the manuscript. Tap4Life, a non-profit organisation, is funded by donations.

Competing interests The authors have no financial relationships relevant to this article to disclose. SMH, NJP, CL, TT and TA are co-founders of the non-profit organisation Tap4Life (www.tap4life.org), which produced the free-of-charge application NeoTap. The authors do not get any salary from Tap4Life.

Patient consent for publication Not required.

Ethics approval The Institutional Review Board of Mulago National Referral Hospital, the Uganda National Council for Science and Technology, the Nationa Drug Authority of Uganda, and the Regional Committee for Research Ethics in Norway (REK South-East 2013/2096 and 2017/989) approved the protocols.

Provenance and peer review Not commissioned; externally peer reviewed.

Data availability statement All data relevant to the study are included in the article or uploaded as supplementary information.

Open access This is an open access article distributed in accordance with the Creative Commons Attribution Non Commercial (CC BY-NC 4.0) license, which permits others to distribute, remix, adapt, build upon this work non-commercially, and license their derivative works on different terms, provided the original work is properly cited, appropriate credit is given, any changes made indicated, and the use is non-commercial. See: http://creativecommons.org/licenses/by-nc/4.0/.

ORCID iDs

Susanna Myrnerts Höök http://orcid.org/0000-0001-7560-4077

Tobias Alfven http://orcid.org/0000-0002-2328-3512

\section{REFERENCES}

1 WHO. Levels \& Trends in Child Mortality. Report 2018. Estimates developed by the UN Inter-agency Group for Child Mortality Estimation. United Nations Children's Fund WHO, 2018.

2 Lawn JE, Blencowe H, Oza S, et al. Every newborn: progress, priorities, and potential beyond survival. Lancet 2014;384:189-205.

3 Liu L, Oza S, Hogan D, et al. Global, regional, and national causes of child mortality in 2000-13, with projections to inform post-2015 priorities: an updated systematic analysis. Lancet 2015;385:430-40.

4 Lawn JE, Blencowe H, Waiswa P, et al. Stillbirths: rates, risk factors, and acceleration towards 2030. Lancet 2016;387:587-603.

5 Bhutta ZA, Black RE. Newborn, and child health-so near and yet so far. N Engl J Med 2013;369:2226-35

6 Saugstad OD, Ramji S, Rootwelt T, et al. Response to resuscitation of the newborn: early prognostic variables. Acta Paediatr 2005;94:890-5.

7 Wyckoff MH, Aziz K, Escobedo MB, et al. Part 13: neonata resuscitation: 2015 American heart association guidelines update fo cardiopulmonary resuscitation and emergency cardiovascular care. Circulation 2015;132:S543-60.

8 Linde JE, Perlman JM, Øymar K, et al. Predictors of 24-h outcome in newborns in need of positive pressure ventilation at birth. Resuscitation 2018;129:1-5.

9 Wyllie J, Perlman JM, Kattwinkel J, et al. Part 7: neonatal resuscitation: 2015 international consensus on cardiopulmonary resuscitation and emergency cardiovascular care science with treatment recommendations. Resuscitation 2015;95:e169-201.

10 Kamlin COF, Dawson JA, O'Donnell CPF, et al. Accuracy of pulse oximetry measurement of heart rate of newborn infants in the delivery room. J Pediatr 2008;152:756-60.

11 Singh JKSB, Kamlin COF, Morley CJ, et al. Accuracy of pulse oximetry in assessing heart rate of infants in the neonatal intensive care unit. J Paediatr Child Health 2008;44:273-5.

12 Boon W, McAllister J, Attar MA, et al. Evaluation of heart rate assessment timing, communication, accuracy, and clinical decisionmaking during high fidelity simulation of neonatal resuscitation. Int $J$ Pediatr 2014;2014:1-5.

13 Owen CJ, Wyllie JP. Determination of heart rate in the baby at birth. Resuscitation 2004;60:213-7.

14 Chitkara R, Rajani AK, Oehlert JW, et al. The accuracy of human senses in the detection of neonatal heart rate during standardized simulated resuscitation: implications for delivery of care, training and technology design. Resuscitation 2013;84:369-72.

15 Voogdt KGJA, Morrison AC, Wood FE, et al. A randomised, simulated study assessing auscultation of heart rate at birth. Resuscitation 2010:81:1000-3.

16 Hawkes GA, Hawkes CP, Kenosi M, et al. Auscultate, palpate and TAP: time to re-evaluate. Acta Paediatr 2016;105:178-82.

17 Munabi-Babigumira S, Glenton C, Lewin S, et al. Factors that influence the provision of intrapartum and postnatal care by skilled birth attendants in low- and middle-income countries: a qualitative evidence synthesis. Cochrane Database Syst Rev 2017;11:CD011558.

18 Kevat AC, Bullen DVR, Davis PG, et al. A systematic review of novel technology for monitoring infant and newborn heart rate. Acta Paediatr 2017;106:710-20.

19 Phillipos E, Solevåg AL, Pichler G, et al. Heart rate assessment immediately after birth. Neonatology 2016;109:130-8.

20 . Available: www.tap4life.org

21 Pejovic NJ, Trevisanuto D, Lubulwa C, et al. Neonatal resuscitation using a laryngeal mask airway: a randomised trial in Uganda. Arch Dis Child 2018;103:255-60.

22 Number of mobile phone users worldwide from 2013 to 2019 (in billions), 2016. Available: www.statista.com

23 Binotti M, Cavallin F, Ingrassia PL, et al. Heart rate assessment using NeoTapAdvancedSupport: a simulation study. Arch Dis Child Fetal Neonatal Ed 2019:104:F440-2.

24 Myrnerts Höök S, Pejovic NJ, Marrone G, et al. Accurate and fast neonatal heart rate assessment with a smartphone-based application - a manikin study. Acta Paediatr 2018;107:1548-54.

25 Cavallin F, Binotti M, Ingrassia PL, et al. Impact of a mobile application for heart rate assessment in simulated neonatal resuscitation: a randomised controlled cross-over study. Arch Dis Child Fetal Neonatal Ed 2020;105:41-4

26 Johnson PA, Morina N, O'Reilly M, et al. Evaluation of a Tap-Based smartphone APP for heart rate assessment during asphyxia in a porcine model of neonatal resuscitation. Front Pediatr 2019;7:453.

27 Pejovic NJ, Myrnerts Höök S, Byamugisha J, et al. Neonatal resuscitation using a supraglottic airway device for improved mortality and morbidity outcomes in a low-income country: study protocol for a randomized trial. Trials 2019;20:444.

28 . Available: www.random.org

29 Brunette W, Sudar S, Sundt M, et al. Open data kit 2.0. Proceedings of the 15th Annual International Conference on Mobile Systems, Applications, and Services - MobiSys '17, 2017.

30 R Core Team. R: a language and environment for statistical computing. Austria: R Foundation for Statistical Computing V, 2018.

31 Kamlin COF, O'Donnell CPF, Everest NJ, et al. Accuracy of clinical assessment of infant heart rate in the delivery room. Resuscitation 2006;71:319-21.

32 Murphy MC, De Angelis L, McCarthy LK, et al. Comparison of infant heart rate assessment by auscultation, ECG and oximetry in the delivery room. Arch Dis Child Fetal Neonatal Ed 2018;103:F490-2.

33 Johnson PA, Cheung P-Y, Lee T-F, et al. Novel technologies for heart rate assessment during neonatal resuscitation at birth - A systematic review. Resuscitation 2019;143:196-207.

34 Myrnerts Höök S, Påfs J, Namusoko S, et al. Midwives' capability, opportunity and motivation to perform evidence-based neonatal resuscitation in a low resource setting: a qualitative study. Baltimore, USA: PAS, 2019.

35 Reisman J, Arlington L, Jensen L, et al. Newborn resuscitation training in resource-limited settings: a systematic literature review. Pediatrics 2016;138. doi:10.1542/peds.2015-4490

36 Mduma E, Ersdal H, Svensen E, et al. Frequent brief on-site simulation training and reduction in 24-h neonatal mortality--an educational intervention study. Resuscitation 2015;93:1-7.

37 Skåre C, Boldingh A-M, Nakstad B, et al. Ventilation fraction during the first $30 \mathrm{~S}$ of neonatal resuscitation. Resuscitation 2016;107:25-30.

38 Mizumoto $\mathrm{H}$, Tomotaki S, Shibata $\mathrm{H}$, et al. Electrocardiogram shows reliable heart rates much earlier than pulse oximetry during neonatal resuscitation. Pediatr Int 2012;54:205-7.

39 Katheria A, Rich W, Finer N. Electrocardiogram provides a continuous heart rate faster than oximetry during neonatal resuscitation. Pediatrics 2012;130:e1177-81.

40 van Vonderen JJ, Hooper SB, Kroese JK, et al. Pulse oximetry measures a lower heart rate at birth compared with electrocardiography. J Pediatr 2015;166:49-53. 